\title{
Traumatic Distress, Alexithymia, Dissociation, and Risk of Addiction During the First Wave of COVID-19 in Italy: Results from a Cross-sectional Online Survey on a Non-clinical Adult Sample
}

\author{
Valentina Lucia La Rosa ${ }^{1}$ - Alessio Gori ${ }^{2}$ Palmira Faraci ${ }^{3}$. Carmelo Mario Vicario ${ }^{4}$. \\ Giuseppe Craparo ${ }^{3}$
}

Accepted: 3 June 2021 / Published online: 10 June 2021

(C) The Author(s), under exclusive licence to Springer Science+Business Media, LLC, part of Springer Nature 2021

\begin{abstract}
This study aimed to explore the prevalence of post-traumatic distress, alexithymia, dissociation, and addictive behaviors during the stressful situation of the COVID-19 pandemic. It also aimed to determine whether trauma, alexithymia, and dissociation can effectively predict the risk of addiction in non-clinical subjects during the COVID-19 pandemic. Two hundred nineteen subjects completed a web survey during the first COVID-19 lockdown in Italy, including the Impact of Event Scale-Revised (IES-R), the Dissociative Experience Scale-II (DES-II), and the Addictive Behavior Questionnaire (ABQ). Females reported higher levels of COVID-19-related traumatic stress than males $(p=0.009)$. A greater fear of getting COVID-19 was associated with significantly high IES-R scores $(p<0.0005)$. IES-R total score was significantly lower in the "not internetaddicted" group than that in the "internet-addicted" group $(p<0.0005)$. Furthermore, DES-II total score was significantly higher in the "internet-addicted" group than that in the "non internet-addicted" group $(p<0.0005)$. No statistically significant score differences were highlighted in the "alcohol" group. Future research with longitudinal studies and larger samples will have to clarify whether trauma, alexithymia, and dissociation can effectively predict the risk of addiction in non-clinical subjects during the COVID-19 pandemic.
\end{abstract}

Keywords COVID-19 $\cdot$ Addiction $\cdot$ Alexithymia $\cdot$ Trauma $\cdot$ Dissociation

COVID-19 is the name of a new acute respiratory syndrome caused by the novel SARS-CoV2 coronavirus (Zheng, 2020). After its first appearance in Wuhan, China, this virus quickly spread to all countries of the world, and on March 11, 2020, the World Health Organization declared the outbreak of COVID-19 a pandemic (World Health Organization, 2020a). The

Giuseppe Craparo

giuseppe.craparo@unikore.it

Extended author information available on the last page of the article 
various countries of the world have adopted more or less restrictive measures to contain the contagion, including physical distancing, reorganization of healthcare systems, lockdown, and emergency plans to deal with the pandemic's economic fallout (World Health Organization, 2020b). As a result of these restrictions, millions of people remained isolated at home, and their usual routines were drastically and dramatically modified (Bivia-Roig et al., 2020).

Italy was the first European country heavily hit by the COVID-19 pandemic. Since February 2020, several waves of contagion have affected all Italian regions with an almost uniform spread throughout the country. Numerous periods of both national and local lockdowns have occurred over the last year, with several limitations to people's personal and social life (Stefana et al., 2020). The main indication given by governments to citizens was to stay at home and to avoid meeting people who do not belong to their own family. As a result, about 60 million Italians have been forced to lockdown (Paterlini, 2020): people were allowed to leave their homes only for essential activities such as shopping for food or serious health reasons; furthermore, many workers were forced to work remotely from home in "smart working" mode (Cancello et al., 2020) as well as all schools and universities were closed and all educational activities, such as lessons and exams, have adapted to online modalities (Commodari \& La Rosa, 2020).

The literature on quarantine's psychological impact reported adverse effects on people's mental health, including post-traumatic stress symptoms, confusion, anger, fear, nervousness, depression, and irritability (Brooks et al., 2020; Hawryluck et al., 2004; Liu et al., 2012). In this regard, several authors believe that health policy strategies for pandemic containment based on social distancing, home confinement, and quarantine will worsen mental health and increase addiction problems worldwide (Holmes et al., 2020; Rodriguez et al., 2020).

Recent studies conducted on drinking and addictive behaviors during the COVID-19 pandemic showed an increase in alcohol consumption in this period compared to last year (Rodriguez et al., 2020). Similarly, it has been underlined that hours spent on the internet, smartphones, online and offline gaming, and video viewing significantly increased during the lockdown period, with an increased risk of developing addictive behaviors (Higuchi et al., 2020; King et al., 2020; Price, 2020).

A possible explanation for an increased risk of addictive behaviors during COVID-19 quarantine can be found in the Self-Medication Hypothesis (Khantzian, 1997). The addictive disorders represent a remedy that the subject adopts to get relief from painful effects or to experience or control emotions. In this scenario, social distancing and home confinement measures during the COVID-19 pandemic can be associated with stress and uncertainty (Taylor, 2019) as well as with anxiety and depressive symptoms (Brooks et al., 2020), and those most vulnerable may be more likely to cope with these feelings through addictive behaviors (Rodriguez et al., 2020).

The most recent literature on pathological addictions has largely confirmed the role of trauma, dissociation, and alexithymia in the onset of addictive behaviors such as alcoholism and internet addiction (Craparo, Ardino, et al., 2014a; Zdankiewicz-Scigala \& Scigala, 2018).

According to these studies, addiction may be considered a dissociative behavior related to alexithymia and developmental trauma (Craparo, Ardino, et al., 2014a). More specifically, it has been demonstrated that early traumatic experiences interfere with the development of cognitive and affective processing, the integration of thinking and feeling, and the capacity to understand and express emotional states (Craparo, Ardino, et al., 2014a). These difficulties are related to post-traumatic reactions, dissociation, and alexithymia (Yates, 2009). 
Alexithymia is defined as a deficit in the cognitive processing of emotion, characterized by difficulty identifying and describing feelings and externally oriented thinking, and poor imaginal processes (Messina et al., 2014; Taylor et al., 2009). Individuals with a high level of alexithymia may attempt to regulate their emotional states behaviorally rather than cognitively (Zdankiewicz-Scigala \& Scigala, 2018). In this regard, ample evidence exists to prove that alexithymia plays an essential role in the etiopathogenesis of addictive disorders (Mahapatra \& Sharma, 2018; Marchetti et al., 2019; Thorberg et al., 2011).

Recently, alexithymia has been examined as a possible predictor of dissociative tendencies (Evren et al., 2008; Grabe et al., 2000). Dissociation is defined as splitting normally integrated functions of awareness, memory, and identity and is considered a defense mechanism against intolerable, trauma-associated memories and feelings (Grabe et al., 2000). Several studies confirmed the strong association between alexithymia and dissociation in addicted subjects (Evren et al., 2008) and the significant role of traumatic experiences in the onset of these disorders.

More specifically, traumatic experiences confront the subject unexpectedly with death, a risk to life, or threat to physical and mental integrity, and may cause difficulty in regulating emotional states and tolerating negative emotions. Alexithymia and dissociation may overlap in the process of handling stressful situations, contributing, at the same time, to the increase of deficits in the affective and cognitive sphere of behavior regulation and to the possible development of addictive behaviors (Craparo, Ardino, et al., 2014a; Evren et al., 2008; Zdankiewicz-Scigala \& Scigala, 2018; Zdankiewicz-Ścigała \& Ścigała, 2020).

In light of these considerations, this study aimed to investigate the psychological impact of the COVID-19 pandemic and the relationship between the distress related to COVID-19 and addictive behaviors (alcoholism, internet addiction, gambling) in a non-clinical adult sample. In particular, according to the literature on the relationship between traumatic experiences, alexithymia, dissociation, and addiction risk (Craparo, 2011; Craparo, Ardino, et al., 2014a; Evren et al., 2008; Zdankiewicz-Scigala \& Scigala, 2018; Zdankiewicz-Ścigała \& Ścigała, 2020), this study explored the role of post-traumatic distress, alexithymia, and dissociation as risk factors for the onset of addictive behaviors in response to the stressful situation of the COVID-19 pandemic.

\section{Materials and Methods}

This cross-sectional, observational study was conducted using a web survey developed through Google Forms. The survey was posted on the leading social media platforms and shared via email. Participants completed an anonymous online questionnaire between March 22 and May 4, 2020, during the so-called phase 1 of the lockdown in Italy, during which people had to stay at home and shops, restaurants, bars, gyms, and other recreational places were closed. We recruited adults with an adequate understanding of the Italian language. People with psychiatric or psychological disorders and psychotropic drug therapy were excluded from the sample based on the answer they gave to a preliminary question. Participation in the study was strictly voluntary, anonymous, and with no remuneration. The study was performed following the ethical standards of the 1964 Declaration of Helsinki. All participants completed an online informed consent form. The Ethics Committee of the Kore University of Enna approved the study protocol. 


\section{Measures}

The survey included a first section consisting of 17 questions about the sociodemographic data of the participants (age, gender, education, current work conditions, number of cohabitants, size of the house, the occurrence of COVID-19 infection among relatives/friends/himself, changes in work activity, and frequency of leaving home after government lockdown measures). The second section of the survey included a battery of standardized questionnaires to evaluate the subjective distress related to the COVID-19 pandemic, alexithymia levels, dissociative experiences, and addictive behaviors. More specifically, the following questionnaires were used in the study:

Impact of Event Scale-Revised (IES-R) The IES-R (Creamer et al., 2003) is a revised version of the IES, developed by Horowitz et al. (Horowitz et al., 1979). It is a 22-item self-report measure that evaluates the subjective impact of several traumatic experiences (Sundin \& Horowitz, 2002, 2003). All items are answered on a five-point scale ranging from $0=$ "not at all" to 4 = "extremely." The higher the score, the higher the psychological distress. The total score of IES-R ranges from 0 to 88 and is composed of three subscores (Intrusion, Avoidance, and Hyperarousal). The Italian version of the IES-R was used in this study with good psychometric properties (Craparo et al., 2013). More in detail, the IES-R scales showed satisfactory values of internal consistency (Intrusion, Cronbach's $\alpha=.78$; Avoidance, Cronbach's $\alpha=.72$; Hyperarousal, Cronbach's $\alpha=.83$ ) and acceptable values of convergent validity (Craparo et al., 2013). In light of the study's objectives, the questionnaire has been specifically adapted to the COVID-19 pandemic.

Toronto Alexithymia Scale - 20 (TAS-20) A 20-item questionnaire that is the most common tool for assessing alexithymia (Bagby et al., 1994). Each item is graded according to a fivepoint Likert-type scale ranging from $1=$ "strongly disagree" to $5=$ "strongly agree." Total scores range from 20 to 100 , with a score $\geq$ of 61 indicative of alexithymia and scores between 51 and 60 of borderline alexithymia. The TAS-20 comprises three factors: F1, difficulty in identifying feelings; F2, difficulty in describing feelings to others; F3, externally oriented thinking style. The present study used the Italian adaptation of TAS-20 (Bressi et al., 1996; Caretti \& Barbera, 2005). The internal consistency of the Italian version of the questionnaire is good (Cronbach's $\alpha=.81$ ) and has the same three-factor structure as the original English version (Bressi et al., 1996; Caretti \& Barbera, 2005).

Dissociative Experience Scale-II (DES-II) The DES-II (Carlson \& Putnam, 1993) is a selfreport questionnaire to assess dissociative experiences such as depersonalization, derealization, compartmentalization, and amnesia. It consists of 28 items, and each item assesses the percentage of time the subject experiences dissociative symptoms. The overall score of the DES-II ranges from 0 to $100 \%$, and the average score is obtained by adding up the 28 item scores and dividing that total by 28 . This study used the Italian version of the questionnaire, which was largely applied with both clinical and non-clinical populations (Craparo et al., 2013; Craparo, Ardino, et al., 2014a; Craparo, Gori, et al., 2014b). The Italian adaptation of DES-II showed an excellent internal consistency (Cronbach's $\alpha=.94$ ) and good reliability (SpearmanBrown split-half reliability $=.89$; average inter-item correlation $=.37)($ Schimmenti, 2015). 
Addictive Behavior Questionnaire (ABQ) The ABQ (Caretti et al., 2018) is a self-report questionnaire that assesses the different forms of addiction. It consists of two parts: the Severity Index (SI) and the Seven Domains Addiction Scale (7DAS). SI is used to assess the current severity of addiction in four main areas: psychoactive substances, alcohol, gambling, internet. Each area comprises two sections: section A assesses the addictive behavior; section B assesses seven domains of psychopathology that are significant for understanding and treating addictive behaviors. The seven domains of the 7DAS, included in section B of ABQ, are Separation anxiety, Affect dysregulation, Somatoform and psychological dissociation, Childhood traumatic experiences, Impulse dyscontrol, Compulsive behavior and ritualization, and Obsessive thoughts (Caretti et al., 2016). The psychometric properties of the Italian version of ABQ were evaluated by Caretti et al. (2018). More specifically, Cronbach's $\alpha$ coefficients for the scales of the SI suggested good reliability (Alcohol, Cronbach's $\alpha=.87$; Gambling, Cronbach's $\alpha=.93$; Internet, Cronbach's $\alpha=.84$ ). Furthermore, SI showed satisfactory convergent and discriminant validity (Caretti et al., 2018).

\section{Statistical Analyses}

The sample size has been calculated on the basis of the primary objective of evaluating the prevalence of post-traumatic distress during the COVID-19 pandemic. In more detail, $N=219$ is an appropriate dimension to detect a prevalence of $15 \%$, as reported in the study by Zhang et al. (2021), with a confidence level of $95 \%$ and a margin of error of 4.72 .

The sample will be described in its clinical and demographic features using descriptive statistics techniques. Quantitative variables will be described using the following measures: minimum, maximum, range, mean, and standard deviation. Qualitative variables will be summarized with absolute and percentage frequency tables. The normality of continuous variables was checked using the Kolmogorov-Smirnov test. Comparisons of questionnaire scores of participants with alcohol/internet-related addictive behavior have been performed with the Mann-Whitney $U$ test. The same test has been used to compare questionnaire scores between genders. Questionnaire score comparisons between educational levels and occupational status have been performed with the Kruskal-Wallis test. Moreover, participants have been categorized into "having alcohol addictive behavior or not" and "having internet addictive behavior or not" via the ABQ scores. These two new variables have been considered as dependent variables in a logistic regression procedure, considering the following risk factors: age, marital status, educational level, occupational status, fear of being COVID-19 infected, fear that a family member could be infected, TAS-20, IES-R, and DES-II total scores.

All the analyses were performed using the Statistical Package for the Social Sciences (SPSS), version 25.0 (IBM Corporation, Armonk, NY).

\section{Results}

A total of 219 subjects without a clinical diagnosis of addiction have been included in the study. Sixty-seven were males (30.6\%) and 152 females (69.4\%). The respondents' mean age was 37.55 years $(\mathrm{SD}=12.7)$, with a minimum age of 20 and a maximum of 80 years. Most of the participants were "single," meaning without any emotional/love bond with another person $(115 ; 52.5 \%)$. The majority of respondents $(81 ; 37.0 \%)$ had a master's degree and were self- 
employed $(68 ; 31.1 \%)$, and most of them have not been affected by COVID-19 (216; 98.6\%). More details are shown in Table 1.

Table 2 presents results related to the lockdown experience. Most of the participants (83; $37.9 \%$ ) claimed to be "moderately" afraid of being infected by COVID-19, and 95 respondents (43.4\%) claimed to be "moderately" afraid that COVID-19 could infect a family member. Most of the respondents continued their work from home $(85 ; 38.8 \%)$ and left the house only once a week $(90 ; 41.1 \%)$ during the lockdown.

Table 3 reports mean values and standard deviations for each questionnaire scores for the whole sample. All the mean values were not classifiable as pathological, although the mean IES-R score is close to the cut-off of 33, indicating a possible diagnosis of post-traumatic stress disorder (PTSD) (30.56 \pm 1.40$)$.

Concerning the addictive behaviors analyzed in this study, 128 responders $(58.4 \%)$ were found to use alcohol in an addictive way during the lockdown period, and 170 participants (77.6\%) were found to use the internet in an addictive way. Only $3(1.4 \%)$ participants were found to use gambling in an addictive way.

Table 1 Sociodemographic characteristics of the sample

\begin{tabular}{|c|c|c|}
\hline & & $N=219$ \\
\hline Gender & $\begin{array}{l}\text { Female } \\
\text { Male }\end{array}$ & $\begin{array}{l}152(69.4) \\
67(30.6)\end{array}$ \\
\hline Age (years old) & & $37.55 \pm 0.86$ \\
\hline \multirow[t]{5}{*}{ Marital status } & Single & $115(52.5)$ \\
\hline & Married & $56(25.6)$ \\
\hline & Separated & $9(4.1)$ \\
\hline & Divorced & $5(2.3)$ \\
\hline & Cohabitant & $34(15.5)$ \\
\hline \multirow[t]{6}{*}{ Level of education } & Primary school & $0(0)$ \\
\hline & Lower secondary school & $5(2.3)$ \\
\hline & Upper secondary school & $41(18.7)$ \\
\hline & Bachelor degree & $27(12.3)$ \\
\hline & Master's degree & $81(37.0)$ \\
\hline & Post-graduate degree & $65(29.7)$ \\
\hline \multirow[t]{12}{*}{ Professional condition } & Unemployed & $12(5.5)$ \\
\hline & Looking for first job & $11(5.0)$ \\
\hline & Entrepreneur & $3(1.4)$ \\
\hline & Self-employed & $68(31.1)$ \\
\hline & Employee & $56(25.6)$ \\
\hline & Artisan & $2(0.9)$ \\
\hline & Trader & $7(3.2)$ \\
\hline & Healthcare professionals & $14(6.4)$ \\
\hline & Housewife & $1(0.5)$ \\
\hline & Student & $26(11.9)$ \\
\hline & Retired & $7(3.2)$ \\
\hline & Educator & $12(5.5)$ \\
\hline \multirow[t]{4}{*}{ Size of the household } & 1 & $26(11.9)$ \\
\hline & 2 & $68(31.1)$ \\
\hline & 3 & $48(21.9)$ \\
\hline & $>3$ & $77(35.2)$ \\
\hline \multirow[t]{2}{*}{ Affected by COVID-19 } & Yes & $3(98.6)$ \\
\hline & No & $216(98.6)$ \\
\hline \multirow[t]{2}{*}{ Family member with Covid-19 } & Yes & $16(7.3)$ \\
\hline & No & $203(92.7)$ \\
\hline
\end{tabular}


Table 2 Frequencies and percentages of changes and experiences related to the COVID-19 lockdown

n $\%$

Are you afraid of being infected with COVID-19?

Not at all

Slightly

18

72

Somewhat

39

Moderately

83

Extremely

7

$\%$

Are you afraid that your family members could contract COVID-19 infection?

Not at all

2

Slightly

Somewhat

Moderately

Extremely

How has your work changed during the lockdown?

I continue to go to the workplace regularly

$39-17.8$

I continue to work from home

$85-38.8$

I had to stop my work

I lost my job

How many times do you leave the house in a week during the lockdown period?

Never

Table 4 presents results from questionnaire scores comparing those who have had addictive behaviors with alcohol/internet and those who have not. No statistically significant score differences were highlighted in the "alcohol" group. However, IES-R total score was significantly lower in the "not internet-addicted" group than that in the "internet-addicted" group (21.57 vs 33.15, $p<.0005)$; in more details, also the IES-R Intrusion, IES-R Avoidance, and IES-R Hyperarousal scores were significantly different ((7.65 vs $11.75, p=.002)$, (8.16 vs $11.90, p=.002)$, and $(5.76$ vs $9.49, p<.0005))$ for the "not internet-addicted" group versus the "internet-addicted" group, respectively. Furthermore, DES-II total score was significantly

Table 3 Questionnaire scores in the study sample

\begin{tabular}{lr}
\hline Questionnaire score & $n=219$ \\
\hline TAS-20 Alexithymia & $40.77 \pm 0.89$ \\
TAS-20 F1 & $13.89 \pm 0.45$ \\
TAS-20 F2 & $10.91 \pm 0.30$ \\
TAS-20 F3 & $15.97 \pm 0.33$ \\
IES-R Intrusion & $10.84 \pm 0.55$ \\
IES-R Avoidance & $11.06 \pm 0.52$ \\
IES-R Hyperarousal & $8.66 \pm 0.42$ \\
IES-R Total score & $30.56 \pm 1.40$ \\
DES-II Total score & $14.19 \pm 0.90$ \\
ABQ - SI Alcohol & $2.42 \pm 0.33$ \\
ABQ - SI Gambling & $0.04 \pm 0.04$ \\
ABQ - SI Internet & $4.33 \pm 0.35$ \\
\hline
\end{tabular}

Data are described as mean \pm standard deviation

Abbreviations: TAS-20, Toronto Alexithymia Scale-20; IES-R, Impact of Event Scale - Revised; DES-II, Dissociative Experiences Scale - II; $A B Q$, Addictive Behavior Questionnaire; SI, Severity Index 
Table 4 Differences in questionnaire scores among alcohol and internet users

\begin{tabular}{|c|c|c|c|c|c|c|c|c|c|c|}
\hline & \multicolumn{2}{|c|}{$\begin{array}{l}\text { Not alcohol } \\
\text { addicted }(n=91)\end{array}$} & \multicolumn{2}{|c|}{$\begin{array}{l}\text { Alcohol } \\
\text { addicted } \\
(n=128)\end{array}$} & \multirow[t]{2}{*}{$p$ value } & \multicolumn{2}{|c|}{$\begin{array}{l}\text { Not internet } \\
\text { addicted }(n=49)\end{array}$} & \multicolumn{2}{|c|}{$\begin{array}{l}\text { Internet } \\
\text { addicted } \\
(n=170)\end{array}$} & \multirow[t]{2}{*}{$p$ value } \\
\hline & $M$ & $S D$ & $M$ & $S D$ & & $M$ & $S D$ & $M$ & $S D$ & \\
\hline TAS-20 total score & 41.1 & 13.0 & 40.5 & 13.4 & .64 & 40.7 & 13.9 & 40.7 & 13.1 & .72 \\
\hline TAS-20 F1 & 14.1 & 6.4 & 13.7 & 6.8 & .39 & 14.3 & 7.3 & 13.7 & 6.5 & .70 \\
\hline TAS-20 F2 & 10.8 & 4.3 & 10.9 & 4.5 & .99 & 9.8 & 3.6 & 11.2 & 4.6 & .07 \\
\hline TAS-20 F3 & 16.1 & 4.8 & 15.8 & 4.9 & .68 & 16.5 & 5.8 & 15.7 & 4.6 & .67 \\
\hline IES-R total score & 29.3 & 20.8 & 31.4 & 20.6 & .40 & 21.5 & 16.9 & 33.1 & 21.0 & $<.0005$ \\
\hline IES-R Intrusion & 10.4 & 8.0 & 11.1 & 8.2 & .61 & 7.6 & 6.5 & 11.7 & 8.3 & .002 \\
\hline IES-R Avoidance & 10.5 & 7.7 & 11.4 & 7.8 & .50 & 8.1 & 6.9 & 11.9 & 7.8 & .002 \\
\hline IES-R Hyperarousal & 8.2 & 6.3 & 8.9 & 6.1 & .30 & 5.7 & 4.6 & 9.4 & 6.4 & $<.0005$ \\
\hline DES-II total score & 12.7 & 12.8 & 15.2 & 13.7 & .05 & 10.2 & 12.1 & 15.3 & 13.6 & $<.0005$ \\
\hline
\end{tabular}

Abbreviations: $M=$ mean; $S D=$ standard deviation; TAS-20, Toronto Alexithymia Scale-20; IES-R, Impact of Event Scale - Revised; DES-II, Dissociative Experiences Scale - II

higher in the "internet-addicted" group than that in the "non internet-addicted" group (15.35 vs. $10.20, p<.0005)$.

The comparison of questionnaire mean scores between genders highlighted a statistically significant difference in the IES-R total score (25.5 for males vs. 32.77 for females, $p=.009$ ). Statistically significant differences have been highlighted also comparing questionnaire mean scores between educational level groups. In particular, mean IES-R total scores are statistically significantly different between groups $(p<0.0005)$, and pairwise comparisons highlighted that post-graduate degree mean scores are significantly different from bachelor degree mean scores $(p<.0005)$, and master degree mean scores are significantly different from bachelor degree mean scores $(p=.012)$. Moreover, mean DES-II total scores are statistically significantly different between educational levels $(p<.0005)$, and pairwise comparisons highlighted that post-graduate degree scores are significantly different from upper secondary school scores $(p<.0005)$ and from bachelor's degree scores $(p<.0005)$. See Table 5 for details.

Concerning the questionnaire score differences between occupational status, the mean DES-II total score presented a significant difference $(p=.002)$, and pairwise comparisons highlighted that the self-employed group was significantly different from employees $(p=.021)$ and school staff $(p=.038)$.

Finally, the IES-R mean score is statistically significantly different for various levels of fear of being infected by COVID-19 $(p<.0005)$, with the lowest mean score $(23.33 \pm 20.3)$ recorded in the "not at all" group, and the highest mean IES score $(55.2 \pm 10.3)$ recorded in the "extremely" group.

Logistic regression has been performed considering as dependent variable "having alcohol addictive behavior or not" and "having internet addictive behavior or not" via the ABQ scores. Age, marital status, educational level, occupational status, fear of being COVID-19 infected, fear that a family member could be infected, TAS-20, IES-R, and DES-II total scores were considered independent variables. The logistic procedure is statistically robust as it is supported by the sample size (there are 128 subjects with alcohol addictive behavior and 170 subjects with internet addictive behavior). Both the logistic regression procedures have highlighted no statistically significant relations: in more detail, none of the above-mentioned variables was found to be statistically significant $(p<0.10)$ in the univariate analysis. The logistic regression 


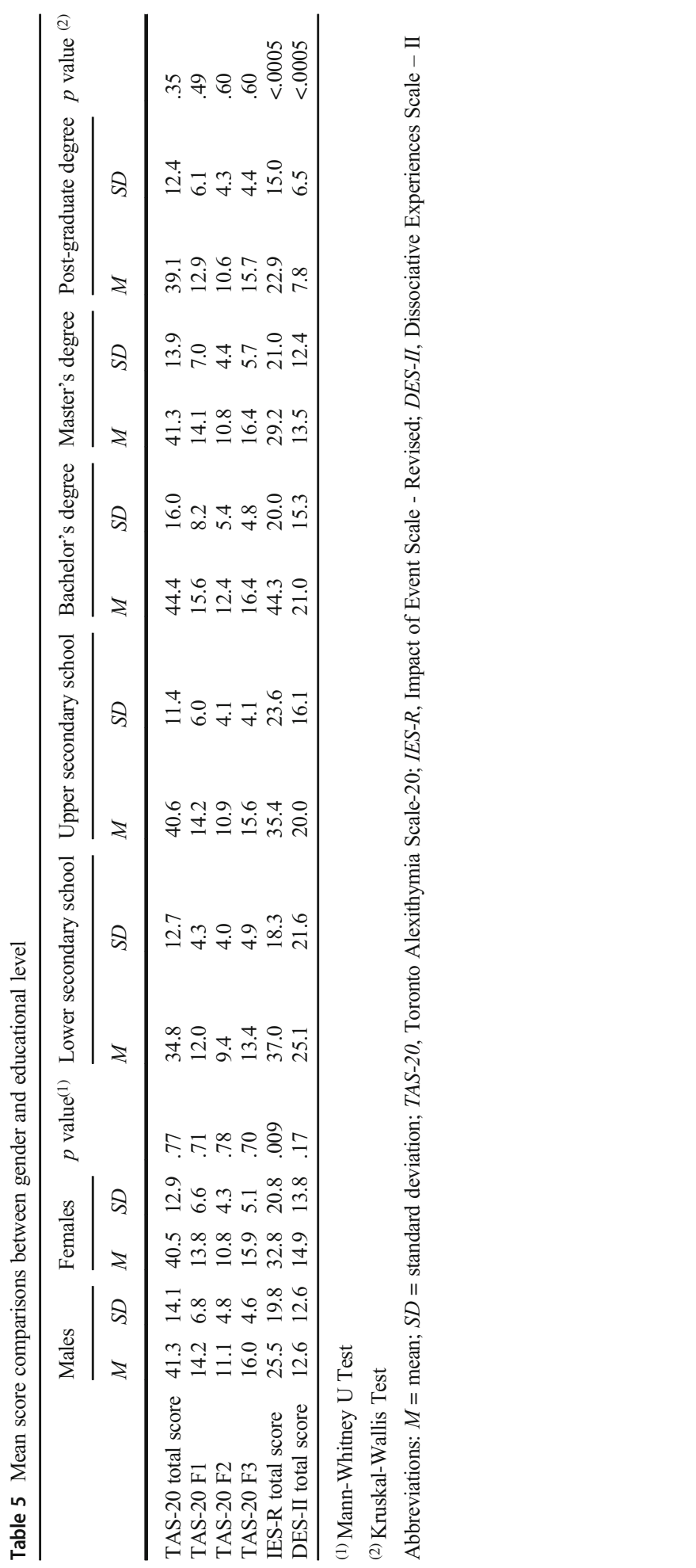


procedure then stopped at the univariate phase. Logistic regression parameters for alcohol and internet addictive behavior are reported in Tables 6 and 7.

\section{Discussion}

This study aimed to explore the psychological impact of the COVID-19 lockdown in terms of the tendency to addictive behaviors in a non-clinical sample. More specifically, we analyzed the relationship between traumatic distress, alexithymia, and dissociation and the influence of these variables on alcohol consumption, internet use, and gambling during the pandemic.

According to the available studies on this topic, this study confirms the significant psychological impact of the COVID-19 pandemic. More specifically, our sample shows moderately high levels of traumatic distress related to the experience of COVID-19. Indeed, the mean score of the IES-R questionnaire was close to the cut-off indicative of a possible diagnosis of PTSD. Furthermore, the subjects with a greater fear of getting COVID-19 reported significantly higher IES-R scores than those who were not worried about the possible contagion. These data confirm that the COVID-19 is a significant traumatic stressor that could lead to PTSD symptomatology (Sar et al., 2021). As underlined in recent studies (Mertens et al., 2020; Sar et al., 2021), COVID-19 can elicit PTSD-like responses even in the absence of direct exposure to the traumatic stressor (e.g., direct contact with the virus). In the specific case of our sample, almost all of the participants had not contracted the virus at the study time. However, the fear of contagion may equally be considered a traumatic stressor. These findings substantially agree with the most recent literature on the psychological impact of COVID-19 on mental health and psychological well-being. Rossi et al. (2020), for example, reported high rates of adverse mental health outcomes, especially post-traumatic stress symptoms, among Italian people during the first weeks of the lockdown.

Females of our sample reported higher levels of COVID-19-related traumatic stress than males. This finding is consistent with the results of previous studies, both from Italy and from other countries, showing a greater vulnerability of the female gender to the psychological impact of the COVID-19 pandemic and a higher prevalence of post-traumatic stress symptoms in women than in men (Liu et al., 2020; Qiu et al., 2020; Rossi et al., 2020; Sar et al., 2021).

Interestingly, the subjects with a lower educational level reported higher traumatic stress and dissociation scores than subjects with a higher educational level. Furthermore, selfemployees showed a greater tendency to dissociation than employees and school staff. This finding can be interpreted in light of the changes in working activity due to the COVID-19 pandemic. Indeed, people with a lower level of education, including students, have suffered the most from the restrictions imposed by the pandemic (Browning et al., 2021; Commodari \& La Rosa, 2020), just as self-employed have suffered the heaviest economic consequences of the lockdown due to loss of work or the temporary closure of their activities. In this regard, recent studies underlined that self-employed individuals reported high levels of anxiety, depression, post-lockdown fears, and paranoia (Alradhawi et al., 2020). Children and students who have experienced the closure of schools and/or universities represent another at-risk group concerning the psychological consequences of the COVID-19 pandemic and whose mental health requires special attention (Alradhawi et al., 2020; Commodari \& La Rosa, 2020).

According to our results, a relevant percentage of the sample reported significant alcohol use and internet use during the confinement period, while only three participants reported gambling. This finding is substantially consistent with other studies on the topic that were 
Table 6 Logistic regression parameters for alcohol addictive behavior

\begin{tabular}{|c|c|c|c|c|c|c|c|c|}
\hline & \multirow[t]{2}{*}{ B } & \multirow[t]{2}{*}{$\mathrm{SE}$} & \multirow[t]{2}{*}{ Wald } & \multirow[t]{2}{*}{ df } & \multirow[t]{2}{*}{$p$} & \multirow[t]{2}{*}{$\begin{array}{l}\text { Odds } \\
\text { ratio }\end{array}$} & \multicolumn{2}{|c|}{$\begin{array}{l}95 \% \text { C.I. for } \\
\text { odds ratio }\end{array}$} \\
\hline & & & & & & & Lower & Upper \\
\hline Age & -0.02 & 0.01 & 3.23 & 1.00 & .07 & 0.98 & 0.96 & 1.00 \\
\hline Constant & 1.08 & 0.43 & 6.19 & 1.00 & .01 & 2.93 & & \\
\hline Marital status & & & 1.21 & 4.00 & .88 & & & \\
\hline Marital status (1) & 0.09 & 0.40 & 0.05 & 1.00 & .83 & 1.09 & 0.50 & 2.37 \\
\hline Marital status (2) & -0.14 & 0.44 & 0.10 & 1.00 & .75 & 0.87 & 0.37 & 2.06 \\
\hline Marital status (3) & -0.58 & 0.76 & 0.59 & 1.00 & .44 & 0.56 & 0.13 & 2.46 \\
\hline Marital status (4) & 0.05 & 0.98 & 0.00 & 1.00 & .96 & 1.05 & 0.15 & 7.13 \\
\hline Constant & 0.36 & 0.35 & 1.05 & 1.00 & .31 & 1.43 & & \\
\hline Level of education & & & 2.20 & 4.00 & .70 & & & \\
\hline Level of education (1) & 0.31 & 0.95 & 0.11 & 1.00 & .74 & 1.37 & 0.21 & 8.73 \\
\hline Level of education (2) & 0.15 & 0.40 & 0.15 & 1.00 & .70 & 1.17 & 0.53 & 2.56 \\
\hline Level of education (3) & 0.60 & 0.48 & 1.58 & 1.00 & .21 & 1.82 & 0.71 & 4.65 \\
\hline Level of education (4) & 0.39 & 0.34 & 1.31 & 1.00 & .25 & 1.47 & 0.76 & 2.85 \\
\hline Constant & 0.09 & 0.25 & 0.14 & 1.00 & .71 & 1.10 & & \\
\hline Professional condition & & & 7.16 & 11.00 & .79 & & & \\
\hline Professional condition (1) & 1.44 & 0.89 & 2.62 & 1.00 & .11 & 4.20 & 0.74 & 23.91 \\
\hline Professional condition (2) & 0.52 & 0.84 & 0.38 & 1.00 & .54 & 1.68 & 0.32 & 8.76 \\
\hline Professional condition (3) & -0.36 & 1.36 & 0.07 & 1.00 & .79 & 0.70 & 0.05 & 10.01 \\
\hline Professional condition (4) & 0.88 & 0.64 & 1.90 & 1.00 & .17 & 2.41 & 0.69 & 8.40 \\
\hline Professional condition (5) & 0.85 & 0.65 & 1.71 & 1.00 & .19 & 2.33 & 0.66 & 8.30 \\
\hline Professional condition (6) & 0.34 & 1.53 & 0.05 & 1.00 & .83 & 1.40 & 0.07 & 28.12 \\
\hline Professional condition (7) & 0.62 & 0.96 & 0.42 & 1.00 & .52 & 1.87 & 0.28 & 12.31 \\
\hline Professional condition (8) & 0.34 & 0.79 & 0.18 & 1.00 & .67 & 1.40 & 0.30 & 6.62 \\
\hline Professional condition (9) & -20.87 & $40,192.97$ & 0.00 & 1.00 & 1.00 & 0.00 & 0.00 & \\
\hline Professional condition (10) & 0.65 & 0.71 & 0.84 & 1.00 & .36 & 1.91 & 0.48 & 7.64 \\
\hline Professional condition (11) & -0.58 & 1.02 & 0.32 & 1.00 & .57 & 0.56 & 0.08 & 4.14 \\
\hline Constant & -0.34 & 0.59 & 0.33 & 1.00 & .57 & 0.71 & & \\
\hline Fear of being infected by COVID-19 & & & 5.10 & 4.00 & .28 & & & \\
\hline Fear of being infected by COVID-19 (1) & -0.98 & 0.91 & 1.15 & 1.00 & .28 & 0.38 & 0.06 & 2.24 \\
\hline Fear of being infected by COVID-19 (2) & 0.05 & 0.80 & 0.00 & 1.00 & .95 & 1.05 & 0.22 & 5.04 \\
\hline Fear of being infected by COVID-19 (3) & 0.29 & 0.83 & 0.12 & 1.00 & .73 & 1.34 & 0.26 & 6.86 \\
\hline Fear of being infected by COVID-19 (4) & 0.18 & 0.80 & 0.05 & 1.00 & .82 & 1.20 & 0.25 & 5.69 \\
\hline Constant & 0.29 & 0.76 & 0.14 & 1.00 & .71 & 1.33 & & \\
\hline $\begin{array}{l}\text { Fear that family members may become } \\
\text { infected with COVID-19 }\end{array}$ & & & 6.30 & 4.00 & .18 & & & \\
\hline $\begin{array}{l}\text { Fear that family members may become } \\
\text { infected with COVID-19 (1) }\end{array}$ & -0.60 & 1.44 & 0.17 & 1.00 & .68 & 0.55 & 0.03 & 9.23 \\
\hline $\begin{array}{l}\text { Fear that family members may become } \\
\text { infected with COVID-19 (2) }\end{array}$ & -0.86 & 0.42 & 4.19 & 1.00 & .42 & 0.43 & 0.19 & 0.96 \\
\hline $\begin{array}{l}\text { Fear that family members may become } \\
\text { infected with COVID-19 (3) }\end{array}$ & -0.69 & 0.51 & 1.84 & 1.00 & .18 & 0.50 & 0.18 & 1.36 \\
\hline $\begin{array}{l}\text { Fear that family members may become } \\
\text { infected with COVID-19 (4) }\end{array}$ & -0.06 & 0.34 & 0.03 & 1.00 & .86 & 0.94 & 0.48 & 1.84 \\
\hline Constant & 0.60 & 0.27 & 5.07 & 1.00 & .02 & 1.82 & & \\
\hline TAS-20 total score & 0.00 & 0.01 & 0.11 & 1.00 & .74 & 1.00 & 0.98 & 1.02 \\
\hline Constant & 0.48 & 0.44 & 1.18 & 1.00 & .28 & 1.62 & & \\
\hline IES-R total score & 0.01 & 0.01 & 0.57 & 1.00 & .45 & 1.01 & 0.99 & 1.02 \\
\hline Constant & 0.19 & 0.24 & 0.60 & 1.00 & .44 & 1.21 & & \\
\hline DES-II total score & 0.01 & 0.01 & 1.79 & 1.00 & .18 & 1.01 & 0.99 & 1.04 \\
\hline Constant & 0.14 & 0.20 & 0.50 & 1.00 & .48 & 1.15 & & \\
\hline
\end{tabular}

Abbreviations: TAS-20, Toronto Alexithymia Scale-20; IES-R, Impact of Event Scale - Revised; DES-II, Dissociative Experiences Scale - II 
Table 7 Logistic regression parameters for internet addictive behavior

\begin{tabular}{|c|c|c|c|c|c|c|c|c|}
\hline & \multirow[t]{2}{*}{ B } & \multirow[t]{2}{*}{ SE } & \multirow[t]{2}{*}{ Wald } & \multirow[t]{2}{*}{ df } & \multirow[t]{2}{*}{$p$} & \multirow[t]{2}{*}{ Odds ratio } & \multicolumn{2}{|c|}{$\begin{array}{l}95 \% \text { C.I. for } \\
\text { odds ratio }\end{array}$} \\
\hline & & & & & & & Lower & Upper \\
\hline Age & -0.02 & 0.01 & 3.77 & 1.00 & .05 & 0.98 & 0.95 & 1.00 \\
\hline Constant & 2.15 & 0.51 & 18.06 & 1.00 & .00 & 8.59 & & \\
\hline Marital status & & & 2.45 & 4.00 & .65 & & & \\
\hline Marital status (1) & 0.26 & 0.45 & 0.33 & 1.00 & .56 & 1.30 & 0.54 & 3.13 \\
\hline Marital status (2) & 0.50 & 0.52 & 0.93 & 1.00 & .33 & 1.66 & 0.59 & 4.61 \\
\hline Marital status (3) & -0.33 & 0.81 & 0.17 & 1.00 & .68 & 0.72 & 0.15 & 3.50 \\
\hline Marital status (4) & -0.62 & 0.99 & 0.39 & 1.00 & .53 & 0.54 & 0.08 & 3.78 \\
\hline Constant & 1.02 & 0.39 & 6.91 & 1.00 & .01 & 2.78 & & \\
\hline Level of education & & & 1.89 & 4.00 & .76 & & & \\
\hline Level of education (1) & 19.72 & $17,974.84$ & 0.00 & 1.00 & 1.00 & $365,767,888.95$ & 0.00 & \\
\hline Level of education (2) & -0.35 & 0.48 & 0.53 & 1.00 & .46 & 0.70 & 0.27 & 1.81 \\
\hline Level of education (3) & 0.00 & 0.59 & 0.00 & 1.00 & .99 & 1.00 & 0.31 & 3.16 \\
\hline Level of education (4) & -0.50 & 0.41 & 1.51 & 1.00 & .22 & 0.61 & 0.27 & 1.34 \\
\hline Constant & 1.49 & 0.32 & 21.59 & 1.00 & .00 & 4.42 & & \\
\hline Professional condition & & & 11.25 & 11.00 & .42 & & & \\
\hline Professional condition (1) & -0.79 & 1.30 & 0.37 & 1.00 & .54 & 0.45 & 0.04 & 5.81 \\
\hline Professional condition (2) & -0.89 & 1.30 & 0.47 & 1.00 & .49 & 0.41 & 0.03 & 5.28 \\
\hline Professional condition (3) & -3.09 & 1.61 & 3.69 & 1.00 & .05 & 0.05 & 0.00 & 1.07 \\
\hline Professional condition (4) & -1.30 & 1.08 & 1.44 & 1.00 & .23 & 0.27 & 0.03 & 2.27 \\
\hline Professional condition (5) & -0.87 & 1.10 & 0.63 & 1.00 & .43 & 0.42 & 0.05 & 3.62 \\
\hline Professional condition (6) & 18.80 & $28,420.72$ & 0.00 & 1.00 & 1.00 & $146,861,349.35$ & 0.00 & \\
\hline Professional condition (7) & -1.48 & 1.34 & 1.23 & 1.00 & .27 & 0.23 & 0.02 & 3.13 \\
\hline Professional condition (8) & -2.40 & 1.17 & 4.18 & 1.00 & .45 & 0.44 & 0.01 & 3.67 \\
\hline Professional condition (9) & 18.80 & $40,192.97$ & 0.00 & 1.00 & 1.00 & $146,861,349.35$ & 0.00 & \\
\hline Professional condition (10) & -0.69 & 1.18 & 0.35 & 1.00 & .56 & 0.50 & 0.05 & 5.03 \\
\hline Professional condition (11) & -1.48 & 1.34 & 1.23 & 1.00 & .27 & 0.23 & 0.02 & 3.13 \\
\hline Constant & 2.40 & 1.04 & 5.27 & 1.00 & .02 & 11.00 & & \\
\hline Fear of being infected by COVID-19 & & & 4.52 & 4.00 & .34 & & & \\
\hline $\begin{array}{l}\text { Fear of being infected by } \\
\text { COVID-19 (1) }\end{array}$ & 1.04 & 1.49 & 0.49 & 1.00 & .49 & 2.83 & 0.15 & 52.74 \\
\hline $\begin{array}{l}\text { Fear of being infected by } \\
\text { COVID-19 (2) }\end{array}$ & -0.90 & 1.11 & 0.66 & 1.00 & .42 & 0.40 & 0.05 & 3.57 \\
\hline $\begin{array}{l}\text { Fear of being infected by } \\
\text { COVID-19 (3) }\end{array}$ & -0.44 & 1.15 & 0.14 & 1.00 & .70 & 0.65 & 0.07 & 6.16 \\
\hline $\begin{array}{l}\text { Fear of being infected by } \\
\text { COVID-19 (4) }\end{array}$ & -0.51 & 1.11 & 0.21 & 1.00 & .65 & 0.60 & 0.07 & 5.33 \\
\hline Constant & 1.79 & 1.08 & 2.75 & 1.00 & .10 & 6.00 & & \\
\hline $\begin{array}{l}\text { Fear that family members may } \\
\text { become infected with COVID-19 }\end{array}$ & & & 0.94 & 4.00 & .92 & & & \\
\hline $\begin{array}{l}\text { Fear that family members may } \\
\text { become infected with } \\
\text { COVID-19 (1) }\end{array}$ & 19.88 & $28,420.72$ & 0.00 & 1.00 & 1.00 & $428,595,366.47$ & 0.00 & \\
\hline $\begin{array}{l}\text { Fear that family members may } \\
\text { become infected with } \\
\text { COVID-19 (2) }\end{array}$ & -0.39 & 0.47 & 0.69 & 1.00 & .41 & 0.68 & 0.27 & 1.71 \\
\hline $\begin{array}{l}\text { Fear that family members may } \\
\text { become infected with } \\
\text { COVID-19 (3) }\end{array}$ & -0.16 & 0.60 & 0.07 & 1.00 & .78 & 0.85 & 0.26 & 2.75 \\
\hline $\begin{array}{l}\text { Fear that family members may } \\
\text { become infected with } \\
\text { COVID-19 (4) }\end{array}$ & -0.01 & 0.40 & 0.00 & 1.00 & .99 & 0.99 & 0.45 & 2.18 \\
\hline Constant & 1.33 & 0.31 & 18.09 & 1.00 & .00 & 3.77 & & \\
\hline TAS-20 total score & 0.00 & 0.01 & 0.00 & 1.00 & .97 & 1.00 & 0.98 & 1.02 \\
\hline
\end{tabular}


Table 7 (continued)

\begin{tabular}{|c|c|c|c|c|c|c|c|c|}
\hline & \multirow[t]{2}{*}{$\mathrm{B}$} & \multirow[t]{2}{*}{ SE } & \multirow[t]{2}{*}{ Wald } & \multirow[t]{2}{*}{ df } & \multirow[t]{2}{*}{$p$} & \multirow[t]{2}{*}{ Odds ratio } & \multicolumn{2}{|c|}{$\begin{array}{l}95 \% \text { C.I. for } \\
\text { odds ratio }\end{array}$} \\
\hline & & & & & & & Lower & Upper \\
\hline Constant & 1.23 & 0.52 & 5.48 & 1.00 & .02 & 3.41 & & \\
\hline IES-R total score & 0.03 & 0.01 & 11.04 & 1.00 & .74 & 1.01 & 0.99 & 1.02 \\
\hline Constant & 0.38 & 0.28 & 1.78 & 1.00 & .18 & 1.46 & & \\
\hline DES-II total score & 0.04 & 0.02 & 5.29 & 1.00 & .45 & 1.04 & 1.01 & 1.07 \\
\hline Constant & 0.79 & 0.24 & 11.09 & 1.00 & .00 & 2.21 & & \\
\hline
\end{tabular}

conducted during the COVID-19 pandemic on non-clinical samples and showed an increase in alcohol consumption (Rodriguez et al., 2020) and the number of hours spent on the internet and smartphones (Higuchi et al., 2020) during the lockdown period. In particular, participants who reported excessive internet use during the lockdown had higher scores for traumatic stress and dissociation. These results seem to confirm a relationship between trauma, dissociation, and a tendency to addictive behaviors related to the internet, as underlined in the literature on this topic (Craparo, 2011; Higuchi et al., 2020). On the other hand, alexithymia does not seem to play a significant role, contrary to what has been reported in the literature (Craparo, 2011; Mahapatra \& Sharma, 2018). Finally, no significant differences were detected in the group of alcohol users.

Contrary to our expectations, the logistic regression model did not identify significant predictors of addiction risk in our sample. A possible interpretation of this finding is that our sample consists of non-clinical subjects, and therefore, the investigated variables may have a different weight compared to clinical samples. Moreover, the study's cross-sectional design did not allow establishing an exact causal relationship between the variables. Future research with longitudinal studies and larger samples will have to clarify whether trauma, alexithymia, and dissociation can effectively predict the risk of addiction in non-clinical subjects during the COVID-19 pandemic.

\section{Strengths and Limitations}

This study is one of the first studies conducted in Italy about the psychological impact of the first wave of the COVID-19 pandemic, focusing on addictive behaviors and the relationship between post-traumatic symptoms and alexithymia, and dissociation. Furthermore, the survey has been conducted during the first lockdown period in Italy and before the progressive reduction of the restriction measures. Therefore, our data provide a detailed overview of the psychological experiences of the subjects interviewed on those particular days.

However, there are also several limitations. The first limitation concerns how the sample was recruited. Indeed, disseminating the survey through social networks and mailing lists excluded people not on social networks and introduced a possible imbalance in the sample composition, for example, in gender. Furthermore, as already underlined, this is a crosssectional study, so an exact causal relationship between the variables could not be established. We also used an internet-based questionnaire with self-reported measures, so the influence of self-report bias on the results should be considered. Finally, we recruited non-addicted subjects in our sample, so the study results should be interpreted, taking into account this data. 


\section{Conclusions}

In conclusion, our study confirms the importance of monitoring mental health and assessing the psychological consequences of unexpected and potentially traumatic events such as the COVID-19 pandemic. In particular, it is essential to ensure adequate preventive and psychological support measures to avoid the development of addictive behaviors due to the negative and unregulated emotions related to the traumatic experience of the pandemic.

Further longitudinal studies are needed to evaluate the impact of this event across time and its role in favoring the onset of pathological addictions. Moreover, it is essential to conduct further studies on addicted individuals and the pandemic's impact on exacerbating these addiction problems.

Author Contribution Conceptualization: Valentina Lucia La Rosa and Giuseppe Craparo; methodology: Valentina Lucia La Rosa; formal analysis and investigation: Valentina Lucia La Rosa and Alessio Gori; writing - original draft preparation: Valentina Lucia La Rosa; writing - review and editing: Palmira Faraci and Carmelo Mario Vicario; Supervision: Giuseppe Craparo.

\section{Declarations}

Ethics Approval All procedures performed in studies involving human participants were in accordance with the ethical standards of the institutional and/or national research committee and with the 1964 Helsinki declaration and its later amendments or comparable ethical standards.

Consent to Participate Informed consent was obtained from all subjects.

Conflict of Interest The authors declare no competing interests.

\section{References}

Alradhawi, M., Shubber, N., Sheppard, J., \& Ali, Y. (2020). Effects of the COVID-19 pandemic on mental wellbeing amongst individuals in society- a letter to the editor on "The socio-economic implications of the coronavirus and COVID-19 pandemic: A review”. International Journal of Surgery, 78, 147-148. https:// doi.org/10.1016/j.ijsu.2020.04.070.

Bagby, R. M., Parker, J. D., \& Taylor, G. J. (1994, Jan). The twenty-item Toronto Alexithymia Scale-I. Item selection and cross-validation of the factor structure. Journal of Psychosomatic Research, 38(1), 23-32. https://doi.org/10.1016/0022-3999(94)90005-1.

Bivia-Roig, G., La Rosa, V. L., Gomez-Tebar, M., Serrano-Raya, L., Amer-Cuenca, J. J., Caruso, S., Commodari, E., Barrasa-Shaw, A., \& Lison, J. F. (2020, Aug 15). Analysis of the impact of the confinement resulting from COVID-19 on the lifestyle and psychological wellbeing of Spanish pregnant women: an internetbased cross-sectional survey. International Journal of Environmental Research and Public Health, 17(16), 5933. https://doi.org/10.3390/ijerph17165933.

Bressi, C., Taylor, G., Parker, J., Bressi, S., Brambilla, V., Aguglia, E., Allegranti, I., Bongiorno, A., Giberti, F., Bucca, M., Todarello, O., Callegari, C., Vender, S., Gala, C., \& Invernizzi, G. (1996). Cross validation of the factor structure of the 20-item Toronto Alexithymia Scale: an Italian multicenter study. Journal of Psychosomatic Research, 41(6), 551-559. https://doi.org/10.1016/s0022-3999(96)00228-0.

Brooks, S. K., Webster, R. K., Smith, L. E., Woodland, L., Wessely, S., Greenberg, N., \& Rubin, G. J. (2020, Mar 14). The psychological impact of quarantine and how to reduce it: rapid review of the evidence. Lancet, 395(10227), 912-920. https://doi.org/10.1016/S0140-6736(20)30460-8.

Browning, M., Larson, L. R., Sharaievska, I., Rigolon, A., McAnirlin, O., Mullenbach, L., Cloutier, S., Vu, T. M., Thomsen, J., Reigner, N., Metcalf, E. C., D’Antonio, A., Helbich, M., Bratman, G. N., \& Alvarez, H. O. 
(2021). Psychological impacts from COVID-19 among university students: risk factors across seven states in the United States. PLoS One, 16(1), e0245327. https://doi.org/10.1371/journal.pone.0245327.

Cancello, R., Soranna, D., Zambra, G., Zambon, A., \& Invitti, C. (2020). Determinants of the lifestyle changes during COVID-19 pandemic in the residents of Northern Italy. International Journal of Environmental Research and Public Health, 17(17), 6287. https://doi.org/10.3390/ijerph17176287.

Caretti, V., \& Barbera, D. L. (2005). Alessitimia. Valutazione e trattamento [Alexithymia. Assessment and treatment]. Astrolabio Ubaldini.

Caretti, V., Craparo, G., Giannini, M., Gori, A., Iraci Sareri, G., Lucchini, A., Rusignuolo, I., \& Schimmenti, A. (2016). ABQ - Addictive Behavior Questionnaire. Manuale e Questionari [ABQ - Addictive Behavior Questionnaire. Manual and Questionnaires]. Hogrefe.

Caretti, V., Gori, A., Craparo, G., Giannini, M., Iraci-Sareri, G., \& Schimmenti, A. (2018). A New Measure for Assessing Substance-Related and Addictive Disorders: The Addictive Behavior Questionnaire (ABQ). Journal of Clinical Medicine, 7(8), 194. https://doi.org/10.3390/jcm7080194.

Carlson, E. B., \& Putnam, F. W. (1993). An update on the Dissociative Experiences Scale. Dissociation: Progress in the Dissociative Disorders, 6(1), 16-27.

Commodari, E., \& La Rosa, V. L. (2020). Adolescents in Quarantine During COVID-19 Pandemic in Italy: Perceived Health Risk, Beliefs, Psychological Experiences and Expectations for the Future. Frontiers in Psychology, 11, 559951. https://doi.org/10.3389/fpsyg.2020.559951.

Craparo, G. (2011). Internet addiction, dissociation, and alexithymia. Procedia - Social and Behavioral Sciences, 30, 1051-1056. https://doi.org/10.1016/j.sbspro.2011.10.205.

Craparo, G., Faraci, P., Rotondo, G., \& Gori, A. (2013). The Impact of Event Scale - Revised: psychometric properties of the Italian version in a sample of flood victims. Neuropsychiatric Disease and Treatment, 9 , 1427-1432. https://doi.org/10.2147/NDT.S51793.

Craparo, G., Ardino, V., Gori, A., \& Caretti, V. (2014a, Jul). The Relationships between Early Trauma, Dissociation, and Alexithymia in Alcohol Addiction. Psychiatry Investigation, 11(3), 330-335. https://oi. org/10.4306/pi.2014.11.3.330.

Craparo, G., Gori, A., Rotondo, G., Mazzola, E., Pellerone, M., \& Petruccelli, I. (2014b). Posttraumatic stress symptoms, dissociation, and alexithymia in an Italian sample of flood victims. Neuropsychiatric Disease and Treatment, 10, 2281-2284. https://doi.org/10.2147/ndt.S74317.

Creamer, M., Bell, R., \& Failla, S. (2003, Dec). Psychometric properties of the Impact of Event Scale - Revised. Behaviour Research and Therapy, 41(12), 1489-1496. https://doi.org/10.1016/j.brat.2003.07.010.

Evren, C., Sar, V., Evren, B., Semiz, U., Dalbudak, E., \& Cakmak, D. (2008). Dissociation and alexithymia among men with alcoholism. Psychiatry and Clinical Neurosciences, 62(1), 40-47. https://doi.org/10.1111/ j.1440-1819.2007.01775.x.

Grabe, H. J., Rainermann, S., Spitzer, C., Gänsicke, M., \& Freyberger, H. J. (2000). The relationship between dimensions of alexithymia and dissociation. Psychotherapy and Psychosomatics, 69(3), 128-131. https:// doi.org/10.1159/000012380.

Hawryluck, L., Gold, W. L., Robinson, S., Pogorski, S., Galea, S., \& Styra, R. (2004, Jul). SARS control and psychological effects of quarantine, Toronto, Canada. Emerging Infectious Diseases, 10(7), 1206-1212. https://doi.org/10.3201/eid1007.030703.

Higuchi, S., Mihara, S., Kitayuguchi, T., Miyakoshi, H., Ooi, M., Maezono, M., Nishimura, K., \& Matsuzaki, T. (2020). Prolonged use of Internet and gaming among treatment seekers arising out of social restrictions related to COVID -19 pandemic. Psychiatry and Clinical Neurosciences., 74, 607-608. https://doi.org/10. 1111/pcn.13127.

Holmes, E. A., O’Connor, R. C., Perry, V. H., Tracey, I., Wessely, S., Arseneault, L., Ballard, C., Christensen, H., Cohen Silver, R., Everall, I., Ford, T., John, A., Kabir, T., King, K., Madan, I., Michie, S., Przybylski, A. K., Shafran, R., Sweeney, A., Worthman, C. M., Yardley, L., Cowan, K., Cope, C., Hotopf, M., \& Bullmore, E. (2020). Multidisciplinary research priorities for the COVID-19 pandemic: a call for action for mental health science. The Lancet Psychiatry, 7(6), 547-560. https://doi.org/10.1016/s2215-0366(20) 30168-1.

Horowitz, M., Wilner, N., \& Alvarez, W. (1979, May). Impact of Event Scale: a measure of subjective stress. Psychosomatic Medicine, 41(3), 209-218. https://oi.org/10.1097/00006842-197905000-00004.

Khantzian, E. J. (1997, Jan-Feb). The self-medication hypothesis of substance use disorders: a reconsideration and recent applications. Harvard Review of Psychiatry, 4(5), 231-244. https://doi.org/10.3109/ 10673229709030550.

King, D. L., Delfabbro, P. H., Billieux, J., \& Potenza, M. N. (2020). Problematic online gaming and the COVID19 pandemic. Journal of Behavioral Addictions, 9(2), 184-186. https://doi.org/10.1556/2006.2020.00016.

Liu, X., Kakade, M., Fuller, C. J., Fan, B., Fang, Y., Kong, J., Guan, Z., \& Wu, P. (2012, Jan). Depression after exposure to stressful events: lessons learned from the severe acute respiratory syndrome epidemic. Comprehensive Psychiatry, 53(1), 15-23. https://doi.org/10.1016/j.comppsych.2011.02.003. 
Liu, N., Zhang, F., Wei, C., Jia, Y., Shang, Z., Sun, L., Wu, L., Sun, Z., Zhou, Y., Wang, Y., \& Liu, W. (2020). Prevalence and predictors of PTSS during COVID-19 outbreak in China hardest-hit areas: gender differences matter. Psychiatry Research, 287, 112921. https://doi.org/10.1016/j.psychres.2020.112921.

Mahapatra, A., \& Sharma, P. (2018). Association of Internet addiction and alexithymia - a scoping review. Addictive Behaviors, 81, 175-182. https://doi.org/10.1016/j.addbeh.2018.02.004.

Marchetti, D., Verrocchio, M. C., \& Porcelli, P. (2019, Aug 7). Gambling problems and alexithymia: a systematic review. Brain Sciences, 9(8). https://doi.org/10.3390/brainsci9080191.

Mertens, G., Gerritsen, L., Duijndam, S., Salemink, E., \& Engelhard, I. M. (2020). Fear of the coronavirus (COVID-19): predictors in an online study conducted in March 2020. Journal of Anxiety Disorders, 74. https://doi.org/10.1016/j.janxdis.2020.102258.

Messina, A., Beadle, J. N., \& Paradiso, S. (2014). Towards a classification of alexithymia: primary secondary and organic. Journal of Psychopathology, 20(1), 38-49.

Paterlini M. (2020). On the front lines of coronavirus: the Italian response to covid-19. BMJ (Clinical research ed.), 368, m1065. https://doi.org/10.1136/bmj.m1065.

Price A. (2020). Online Gambling in the Midst of COVID-19: A Nexus of Mental Health Concerns, Substance Use and Financial Stress. International journal of mental health and addiction, 1-18. Advance online publication. https://doi.org/10.1007/s11469-020-00366-1.

Qiu, J., Shen, B., Zhao, M., Wang, Z., Xie, B., \& Xu, Y. (2020). A nationwide survey of psychological distress among Chinese people in the COVID-19 epidemic: implications and policy recommendations. General Psychiatry, 33(2), e100213. https://doi.org/10.1136/gpsych-2020-100213.

Rodriguez, L. M., Litt, D. M., \& Stewart, S. H. (2020). Drinking to cope with the pandemic: The unique associations of COVID-19-related perceived threat and psychological distress to drinking behaviors in American men and women. Addictive Behaviors, 110, 106532. https://doi.org/10.1016/j.addbeh.2020. 106532.

Rossi, R., Socci, V., Talevi, D., Mensi, S., Niolu, C., Pacitti, F., Di Marco, A., Rossi, A., Siracusano, A., \& Di Lorenzo, G. (2020). COVID-19 pandemic and lockdown measures impact on mental health among the general population in Italy. Frontiers in Psychiatry, 11, 790. https://doi.org/10.3389/fpsyt.2020.00790.

Sar, V., Bridgland, V. M. E., Moeck, E. K., Green, D. M., Swain, T. L., Nayda, D. M., Matson, L. A., Hutchison, N. P., \& Takarangi, M. K. T. (2021). Why the COVID-19 pandemic is a traumatic stressor. PLoS One, 16(1), e0240146. https://doi.org/10.1371/journal.pone.0240146.

Schimmenti, A. (2015). Dissociative experiences and dissociative minds: exploring a nomological network of dissociative functioning. Journal of Trauma \& Dissociation, 17(3), 338-361. https://doi.org/10.1080/ 15299732.2015.1108948.

Stefana, A., Youngstrom, E. A., Hopwood, C. J., \& Dakanalis, A. (2020, Sep). The COVID-19 pandemic brings a second wave of social isolation and disrupted services. European Archives of Psychiatry and Clinical Neuroscience, 270(6), 785-786. https://doi.org/10.1007/s00406-020-01137-8.

Sundin, E. C., \& Horowitz, M. J. (2002, Mar). Impact of Event Scale: psychometric properties. The British Journal of Psychiatry, 180, 205-209. https://doi.org/10.1192/bjp.180.3.205.

Sundin, E. C., \& Horowitz, M. J. (2003, Sep-Oct). Horowitz's Impact of Event scale evaluation of 20 years of use. Psychosomatic Medicine, 65(5), 870-876. https://doi.org/10.1097/01.psy.0000084835.46074.f0.

Taylor, S. (2019). The psychology of pandemics. Preparing for the next global outbreak of infectious disease. Cambridge Scholars Publishing.

Taylor, G. J., Bagby, R. M., Parker, J. D. A., \& Grotstein, J. (2009). Disorders of affect regulation. Alexithymia in Medical and Psychiatric Illness. Cambridge University Press. https://doi.org/10.1017/ cbo9780511526831.

Thorberg, F. A., Young, R. M., Sullivan, K. A., Lyvers, M., Connor, J. P., \& Feeney, G. F. X. (2011). Alexithymia, craving and attachment in a heavy drinking population. Addictive Behaviors, 36(4), 427430. https://doi.org/10.1016/j.addbeh.2010.12.016.

World Health Organization. (2020a). Coronavirus disease 2019 (COVID-19): situation report, 79. https://apps. who.int/iris/handle/10665/331720

World Health Organization. (2020b). WHO Response in Countries. https://www.who.int/emergencies/diseases/ novel-coronavirus-2019/donate/who-response-incountries.

Yates, T. M. (2009). Developmental pathways from child maltreatment to nonsuicidal self-injury. In M. K. Nock (Ed.), Understanding nonsuicidal self-injury: Origins, assessment, and treatment (pp. 117-137). American Psychological Association. https://doi.org/10.1037/11875-007.

Zdankiewicz-Scigala, E., \& Scigala, D. K. (2018). Trauma, temperament, alexithymia, and dissociation among persons addicted to alcohol: mediation model of dependencies. Frontiers in Psychology, 9, 1570. https://oi. org/10.3389/fpsyg.2018.01570. 
Zdankiewicz-Ścigała, E., \& Ścigała, D. K. (2020). Attachment style, early childhood trauma, alexithymia, and dissociation among persons addicted to alcohol: Structural equation model of dependencies. Frontiers in Psychology, 10, 2957. https://doi.org/10.3389/fpsyg.2019.02957.

Zhang, L., Pan, R., Cai, Y., \& Pan, J. (2021). The Prevalence of Post-Traumatic Stress Disorder in the General Population during the COVID-19 Pandemic: A Systematic Review and Single-Arm Meta-Analysis. Psychiatry investigation, 18(5), 426-433. https://doi.org/10.30773/pi.2020.0458.

Zheng, J. (2020). SARS-CoV-2: an emerging coronavirus that causes a global threat. International Journal of Biological Sciences, 16(10), 1678-1685. https://doi.org/10.7150/ijbs.45053.

Publisher's Note Springer Nature remains neutral with regard to jurisdictional claims in published maps and institutional affiliations.

\section{Affiliations}

\section{Valentina Lucia La Rosa ${ }^{1}$ - Alessio Gori ${ }^{2}$ - Palmira Faraci ${ }^{3}$. Carmelo Mario Vicario ${ }^{4}$. Giuseppe Craparo ${ }^{3}$}

1 Department of Educational Sciences, University of Catania, Catania, Italy

2 Department of Health Sciences, University of Florence, Florence, Italy

3 Faculty of Human and Social Sciences, Kore University of Enna, Enna, Italy

4 Department of Cognitive Sciences, Psychology, Education and Cultural Studies, University of Messina, Messina, Italy 